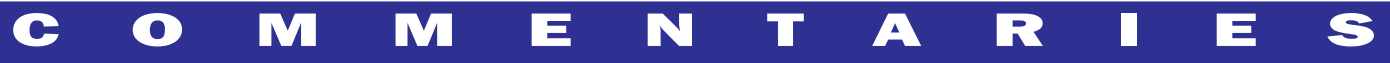

\section{Response to Pamela Fitch}

\section{Reply by Moyer:}

Pamela Fitch makes good points in response to my recent editorial on affective massage therapy (AMT), and I recall that when I was writing it, I wavered on whether to nominate AMT only as a subfield for research or as a subfield for research and practice. I also had, in addition to Fitch's letter, a thought-provoking email exchange on that topic with Dr. Lesley Teitelbaum. Limiting my proposal to research would probably have been less controversial, but then I might have missed out on some interesting correspondence, and so I am happy to court a little controversy.

Fitch expresses concern that a new massage therapy subfield could lead to a lessened appreciation for the importance of skills in therapeutic communication, empathy, and nurturance, but I disagree. I actually think the opposite is more likely. If AMT does evolve into a subfield or specialty area within the diverse profession of massage therapy, I expect that it could actually lead to an even greater understanding of and appreciation for those skills and the ways in which they interact with massage itself to bring about desired changes.

Otherwise, I think that Fitch and I have much we agree on. For example, we share the belief that identifying massage therapists by the techniques they employ is problematic. In fact, this belief was one of my motivations for proposing AMT. I see the possible adoption of AMT as a shift to identification by desired outcome as opposed to identification by technique. The need for this shift parallels my experience as a psychotherapist; I found that only a few patients were curious to know about my theoretical orientation and associated techniques, but all were interested in what psychotherapy might be able to do for them. I suspect, more often than not, the same is true for massage therapy.

Christopher A. Moyer, $\mathrm{PhD}$ Research Section Editor, IJTMB

Assistant Professor

Department of Psychology University of Wisconsin-Stout Menomonie, WI, USA

\section{CONFLICT OF INTEREST NOTIFICATION}

The author declares that there are no conflicts of interest.

\section{COPYRIGHT}

Published under the Creative Commons AttributionNonCommercial-NoDerivs 3.0 License. 